\title{
Does physical exercise improve perceptual skills and visuospatial attention in older adults? A review
}

\author{
Monica Muiños ${ }^{1 *}$ (D) and Soledad Ballesteros ${ }^{2}$
}

\begin{abstract}
Neuroimaging studies suggest that when the brain ages, more areas are involved to perform a task in order to obtain the same results. This, together with the increase in crystalized intelligence and wisdom, is usually considered as a compensatory strategy. Research has demonstrated that physical activity might also act as a strategy and be one of the main factors that can slow down age-related perceptual and cognitive decline. Research also suggests that different types of physical exercise and sport lead to different changes in perceptual and cognitive skills as well as in several areas of the brain, especially those involving multiple domains, such as exergaming, dance or some sports. This review summarizes the findings of recent studies with older adults investigating the brain and cognitive benefits of different forms of physical exercise. Visuospatial attention, which plays a critical role in our daily lives, especially for older adults, is a central part of this analysis.
\end{abstract}

Keywords: Aging, Physical exercise, Martial arts, Visuospatial attention

\section{Background}

The purpose of the present review is to summarize previous and current findings related to changes in visuospatial attention as a function of age and physical exercise and sports activities (especially martial arts). First, we present a brief overview of the adaptation mechanisms used by older adults' brains, which involve functional and structural changes, to adjust to new demands. Second, we review the role of sport and physical exercise in the maintenance of visuospatial abilities that play an important role in well-being and healthy aging. Research with older adults, compared to younger people, could pose a number of challenges. It can be difficult to find older participants engaged in physical activity (PA), especially on a regular basis. Moreover, studies investigating visuospatial aspects such as peripheral vision or dynamic visual acuity in seniors are very scarce. In addition to cognitive and perceptual decline, older adults may suffer from ocular disease, refractive and oculo-motor decline or loss of visual skills. All these factors might contribute to the

\footnotetext{
* Correspondence: monica.muinos@ui1.es

${ }^{1}$ Department of Psychology, Universidad Isabel I, Calle de Fernán González,

76, 09003 Burgos, Spain

Full list of author information is available at the end of the article
}

lack of research investigating PA and visuospatial attention in older adults. One of the main questions in the field of aging and PA concerns the type of exercise that might help to delay age-related cognitive and perceptual decline. This review examines and discusses the effects of aging on visuospatial attention and perceptual skills, and provides an overview of the potential beneficial effects of several types of physical exercise on brain and cognition. Finally, we look in particular at the effects of martial arts training (e.g., karate, judo, tai-chi) on aging and cognition. These topics are rarely dealt with in the area of PA and cognition in old age.

\section{Age-related changes and adaptation mechanisms}

Some cognitive processes, such as verbal abilities and implicit memory, do not decline with age [1-7]. In fact, some factors, such as wisdom and procedural knowledge about how to act in certain situations, even improve with age [8]. Despite these positive results, aging is usually associated with the slowing down of processing speed $[9,10]$, a significant decline in working memory [7] and long-term memory [11], and difficulty inhibiting irrelevant stimuli [12]. Young and older adults show different brain activity when performing verbal working memory [13] and verbal long-term memory tasks $[14,15]$, possibly reflecting 
compensation maneuvers by seniors to obtain similar results as before. Older adults often have a tendency to engage both the left and right hemispheres [13], or even different areas than those used by young adults when performing the same task [7]. To account for these differences in cerebral functioning, Park and Reuter-Lorenz proposed the scaffolding theory $[7,16]$. According to this theory, increased activation, especially in frontal areas, serves as a compensatory mechanism used by older adults to respond to the demands of certain cognitive tasks. However, it has been suggested [17] that such age-related neural dedifferentiation could contribute to rather than compensate for cognitive age-related declines, as the involvement of additional brain regions of older adults might in part be due to the decrease in neuronal selectivity, which would be a consequence of rather than compensation for cognitive decline.

Neuroplasticity may also be considered as a compensatory mechanism. The brain is an adaptable organ, subject to a continuous learning process [18]. Neuroplasticity might modify the brain, both structurally and functionally, to respond to certain needs and demands [18, 19], reducing age-related slowing-down, and even delaying the onset of neurodegenerative diseases [20-22]. It is a learning phenomenon that occurs throughout the life cycle and that persists despite cognitive slowing, varying in its actions between individuals. In fact, large differences may be found as a function of life-style, with some older adults showing severe cognitive losses while others perform similarly to young adults [23, 24]. Cognitive aging, then, may not fully conform to the typically established linear model (from growth to cognitive decline, fluid versus crystallized intelligence, or hardware versus software); on the contrary, seniors may optimize their resources through adaptation and compensation.

A large body of research has found that the preservation of perceptual and cognitive processes can depend on whether the older adults are physically active and whether they have a social lifestyle [1,25-28]. Not only does PA keep the body in better condition and help reduce the risk of certain diseases, but it also has considerable benefits for the cognitive and perceptual abilities of both young $[29,30]$ and older adults $[1,28,31-36]$. Some studies [37] suggest that training can improve the processes associated with fluid intelligence in older people. However, in spite of the ability of the brain to adapt to new demands (neuroplasticity), of older people's advantage in crystallized intelligence, and of their compensatory and optimization strategies, they generally perform at lower levels than young adults. Engaging in physical exercise or PA is one of the pillars of successful aging. Physical activity is an umbrella term that includes a large number of activities related to purposeful body movements [38].
In the following section, we review the role of different types of physical activity in maintaining perceptual and cognitive skills in older adults.

\section{The role of physical exercise in successful aging}

Given the rise of life expectancy, and hence the increased number of older adults, especially in developed societies, the number of people with age-related neurodegenerative diseases is expected to increase dramatically in the coming decades. This makes it urgent to identify ways to improve the quality of life of older adults, their families and carers, by promoting healthy aging. A large number of studies have focused on the importance of regular PA, not only as a way of improving physical health, reducing the risk of cardiovascular and neurodegenerative diseases, and delaying mortality [39], but also of delaying age-related cognitive decline and the onset of neurodegenerative diseases $[19,40]$. See Tables 1 and 2 .

Physical exercise in older adults might act as a "neuroprotector" [20-22], preserving several cognitive functions in the older mind and brain. Specifically, some brain structures involved in the cognitive improvement that occurs with physical exercise (i.e. the hippocampus) are often related to Alzheimer's disease [41]. The hippocampus usually loses weight with age, producing episodic memory declines and increasing the risk of dementia [42-44]. For example, Erickson and colleagues found that the anterior hippocampus of older adults who did aerobic exercises for a year increased by $2 \%$ [43], while the anterior hippocampus of the older group who did stretching exercises during the same period increased by around $1.4 \%$. The same study also yielded different results for these two types of physical exercise for the Brain-Derived Neurotrophic Factor (BDNF), which was higher for the group who did aerobic exercises. Other studies [45] also reported higher BDNF levels for the physically active group as well as an increase in local gray matter in prefrontal areas. BDNF seems to be related to dendritic expansion [46] and to long-term memory [47, 48]. It seems that a single bout of physical exercise has a significantly larger impact on BDNF serum levels than either mindfulness practice or cognitive training [49]. Physical activity produces selective changes that are not uniform across the brain, as improvements are only found in the anterior hippocampus [43]. A recent study [50] also found similar results; that is, that aerobic exercise is associated with increased hippocampus volume and better cognitive functioning. These results suggest that the anterior hippocampus increases more with aerobic exercise than with stretching or toning activities.

PA might affect brain structures other than the hippocampus. There have been fewer studies on the effect of sports on the volume of the basal ganglia, but it seems that motor fitness and coordination training is related to 
Table 1 Characteristics and main findings of core neuroimaging and physical activity studies of older adults

\begin{tabular}{lllll}
\hline Study & $\begin{array}{l}\text { Age } \\
\text { range }\end{array}$ & Number & Type of exercise & Structures/processes investigated \\
\hline $\begin{array}{l}\text { Colcombe } \\
\text { et al. (2004) [33] }\end{array}$ & $58-74$ & 41 & $\begin{array}{l}\text { Aerobic / stretching } \\
\text { and toning }\end{array}$ & $\begin{array}{l}\text { Prefrontal and parietal cortices, } \\
\text { spatial selection and } \\
\text { inhibitory functioning }\end{array}$ \\
$\begin{array}{l}\text { Colcombe et al. 60-79 } \\
\text { (2006) [52] }\end{array}$ & 59 & $\begin{array}{l}\text { Aerobic / toning and } \\
\text { stretching }\end{array}$ & Brain volume \\
$\begin{array}{l}\text { Voss et al. } \\
\text { (2010) [35] }\end{array}$ & $55-80$ & 120 & Aerobic fitness level & $\begin{array}{l}\text { Functional connectivity, executive } \\
\text { function }\end{array}$
\end{tabular}

Significant findings

Highly fit or aerobically trained individuals showed greater task-related activity in prefrontal and parietal cortices, which are involved in spatial selection and inhibitory functioning.

Aerobic exercise increased brain volume in both gray and white matter regions.

Aerobic exercise was associated with functional connectivity on the default mode network, with processing speed and memory.

Erickson et al. $\quad 55-80 \quad 120 \quad$ Aerobic / stretching Hippocampus, spatial memory (2010) [43]

Liu-Ambrose

$65-75$

155 et al. (2010) [57]

Resistance / balance and toning

Brain volume, executive function

Voelcker-

$62-79 \quad 44$

Cardiovascular and coordination training / Rehage et a relaxation and stretching

Ruscheweyh 50-72 $62 \quad$ Aerobic
et al. (2011) [45]

Niemann et al. $\quad 62-79 \quad 70$ (2014) [51]

Eggenberger

$68-82$ et al. (2016) [65]

Niemann et al. (2016) [69]

Schättin et al. (2016) [66]

Rehfeld et al.

$65-71$ (2017) [68] (2017) [50]
Jonason et at.
Cardiovascular and motor fitness / coordination training / stretching and relaxation
Activity in prefrontal areas, executive functioning, perceptual speed

Serum levels of granulocyte colony stimulating factor (G-CSF), brain-derived neurotrophic factor (BDNF), $\mathrm{MRI}$, and episodic memory

Volume of the basal ganglia, executive function and processing speed catecholamines (serum analyses),

balance and stretching training

Aerobic / dancing

Gray matter brain volume, executive function

Prefrontal cortex activity, executive

Cognitive exercises through exergames (videogames) / function

training, balance, motor

Dancing / endurance strength and flexibility training

Volumes of hippocampal subfields and balance abilities

Aerobic exercise increased the size of the anterior hippocampus, BDNF serum levels, and improved spatial memory.

Resistance exercise improved executive function and reduced brain volume to a greater extent than balance and tone exercises.

Cardiovascular and coordination training improved executive functioning and perceptual speed and decreased activation in prefrontal areas.

Aerobic activity was associated with increases in local gray matter volume in prefrontal and cingulate cortex, and BDNF levels, and with enhanced memory.

Motor fitness (and not cardiovascular fitness) was related to the volume of the putamen and the globus pallidus. Motor fitness and coordination training was related to the volume of basal ganglia nuclei and to executive function tasks.

Dancing led to a larger reduction in left prefrontal cortex activity than balance and stretching, associated with improved executive functions.

No differences in gray matter volume between dancing and other aerobic exercises.

Exergame activity was associated with improved cognitive functioning and with greater prefrontal theta activity than classic balance exercises.

Left hippocampal volume increased in both groups but only the dancers showed increases in the left dentate gyrus and the right subiculum, as well as in the balance tests.

Cortical thickness in frontal regions, Aerobic activity, compared to other hippocampus volume, episodic memory, types of exercise, was associated with processing speed, updating, executive increased hippocampus volume and function better cognitive functioning. 
Table 1 Characteristics and main findings of core neuroimaging and physical activity studies of older adults (Continued)

\begin{tabular}{|c|c|c|c|c|c|}
\hline Study & $\begin{array}{l}\text { Age } \\
\text { range }\end{array}$ & Number & Type of exercise & Structures/processes investigated & Significant findings \\
\hline $\begin{array}{l}\text { Müller et al. } \\
\text { (2017) [67] }\end{array}$ & $63-80$ & 22 & $\begin{array}{l}\text { Dance / strength- } \\
\text { endurance and flexibility } \\
\text { training }\end{array}$ & $\begin{array}{l}\text { Gray matter volume, short- and long- } \\
\text { term verbal memory, auditory verbal } \\
\text { learning test, attention tests }\end{array}$ & $\begin{array}{l}\text { Increased gray matter volume in the left } \\
\text { precentral gyrus in dancers than in } \\
\text { controls. Similar results were obtained } \\
\text { in both groups on the attention and } \\
\text { memory tests. }\end{array}$ \\
\hline $\begin{array}{l}\text { Ji et al. (2017) } \\
\text { [25] }\end{array}$ & $60-80$ & 24 & $\begin{array}{l}\text { Wii-fitness exercise that } \\
\text { involves aerobic, balance, } \\
\text { weight lifting, and yoga }\end{array}$ & $\begin{array}{l}\text { Multi-modal imaging measures } \\
\text { Memory and executive function }\end{array}$ & $\begin{array}{l}\text { Exercise reduced losses in several } \\
\text { brain structures, notably the right } \\
\text { striatum and the posterior cingulate, } \\
\text { and improved memory and } \\
\text { executive functions. }\end{array}$ \\
\hline $\begin{array}{l}\text { Håkansson } \\
\text { et al. (2017) [49] }\end{array}$ & $50-79$ & 19 & $\begin{array}{l}\text { Physical exercise / } \\
\text { cognitive training / } \\
\text { mindfulness }\end{array}$ & BDNF serum levels & $\begin{array}{l}\text { Physical exercise increased BDNF } \\
\text { serum levels to a greater extent } \\
\text { than cognitive training or mindfulness. }\end{array}$ \\
\hline $\begin{array}{l}\text { Godde et al. } \\
\text { (2017) [61] }\end{array}$ & $63-79$ & 43 & $\begin{array}{l}\text { Walking / motor } \\
\text { coordination / relaxation } \\
\text { and stretching exercises }\end{array}$ & Brain activation & $\begin{array}{l}\text { Walking and coordination exercises } \\
\text { reduced right dorsolateral prefrontal } \\
\text { cortex activation. }\end{array}$ \\
\hline
\end{tabular}

Note: Studies are organized by publication year. The corresponding reference appears in brackets

the volume of basal ganglia nuclei and with executive function tasks [51].

Colcombe and colleagues [33] found that PA affected brain flexibility and adaptability, possibly by improving vascular capacity and synaptic connections. The results revealed that athletes had higher attentional skills than sedentary participants. In particular, athletes showed better functioning of the prefrontal and parietal cortices and the anterior cingulate cortex, areas involved in attentional processing. Aerobic physical activity also tended to reduce both gray and white matter loss in older adults [52]. It seems then that cardiorespiratory fitness improves the structural integrity of the anterior cingulate [53].

Behavioral studies have also reported positive relationships between aging and physical exercise. For example, aerobic and balance training predicted enhanced processing speed, inhibition and working memory [54]. Older adults with an active life-style performed better on working memory, spatial memory, inhibition capacity, and the ability to switch between tasks [35]. Other findings are in the same line, showing better results for physically active older adults compared to sedentary elders of the same age. In particular, participants exhibited better verbal learning and memory, and better selective attention after 1 year of cardiovascular fitness intervention. Importantly, to maintain these abilities, it is necessary to continue physical activity [31]. A recent study [55] found that both young and older adults performed better in a fine motor task after performing a cardiovascular physical activity.

Thus, most research supports the view that physical activity helps to preserve both physical and cognitive abilities in old age (see Table 2). However, many older adults avoid sports activities, in part due to their insecurity or fear of injury or falls [56]. Some studies argue that aerobic and resistance training slows down age-related declines to a greater extent than other types of exercise [33, 52, 35, 43, 45, 57, 58]. For example, older participants who did resistance activity training performed better on a Stroop task than those doing balance and toning exercises [57]. Moreover, aerobic and resistance activity improves spatial memory, in both animals and humans [58]. Some reviews have also examined the effects of aerobic fitness on cognitive function [59]. Other types of exercise also seem to play an important role in preserving certain perceptual and cognitive skills; in particular, it has been suggested that coordination exercises improve the detection of stimuli in visual search tasks [60]. In a further functional magnetic resonance imaging (fMRI) study [61], it was found that seniors who carried out walking and coordination tasks showed less brain activation in the right dorsolateral prefrontal cortex when performing motor control tasks than those who did stretching exercises. It seems thus that aerobic and coordination exercises might help attenuate age-related cognitive decline. Crucially, the PA should be carried out on a regular basis, since perceptual and cognitive improvements are often reversed shortly after the end of the exercise. Improvements are usually larger when the exercise is performed regularly than when it is carried out in isolation [62]. Surprisingly, some studies reported greater cognitive effectiveness with just one training session [63] and even after 10 minutes of physical exercise [64]. The authors attributed improvements to the connection between the cerebellum, mainly specialized in motor tasks, and the frontal cortex. It seems that when there is greater task complexity, as in coordination exercises, more activity of the prefrontal cortex is required. Physical exercise would thus activate the frontal lobes, responsible for a large number of cognitive tasks. In addition to the studies that examined the individual effects of aerobic, coordination, stretching, balance, or physical 
Table 2 Characteristics and main findings of perceptual and cognitive skills and physical activity studies of older adults

\begin{tabular}{|c|c|c|c|c|}
\hline Study & $\begin{array}{l}\text { Age } \\
\text { range }\end{array}$ & Number & Type of exercise & Structures/processes investigated \\
\hline $\begin{array}{l}\text { Bakken et al., } \\
\text { (2001) [95] }\end{array}$ & $72-91$ & 10 & Aerobic & $\begin{array}{l}\text { Eye tracking with moving } \\
\text { stimulus }\end{array}$ \\
\hline $\begin{array}{l}\text { Roth et al. } \\
\text { (2003) [86] }\end{array}$ & $65-95$ & 50 & Questionnaires to evaluate PA & Peripheral vision \\
\hline $\begin{array}{l}\text { Gauchard et al., } \\
\text { (2003) [99] }\end{array}$ & $66-78$ & 26 & $\begin{array}{l}\text { Yoga, soft gymnastics, jogging, } \\
\text { swimming }\end{array}$ & $\begin{array}{l}\text { Vestibulospinal reflex and ocular } \\
\text { movements related to visual } \\
\text { stimulus }\end{array}$ \\
\hline $\begin{array}{l}\text { Barnes et al. } \\
\text { (2003) [31] }\end{array}$ & $>55$ & 349 & Cardiorespiratory fitness & Attention, executive function \\
\hline
\end{tabular}

\begin{tabular}{|c|c|c|c|c|}
\hline $\begin{array}{l}\text { Owsley \& McGwin } \\
\text { (2004) [90] }\end{array}$ & $55-83$ & 342 & $\begin{array}{l}\text { Questionnaires to evaluate PA, } \\
\text { e.g. asking about household } \\
\text { chores, yard work, exercise-like } \\
\text { walking, golf, swimming, etc. }\end{array}$ & Peripheral vision \\
\hline $\begin{array}{l}\text { Lobjois et al., } \\
\text { (2005) [97] }\end{array}$ & $20-80$ & 24 & $\begin{array}{l}\text { Tennis (aerobic, strength, balance, } \\
\text { coordination) }\end{array}$ & $\begin{array}{l}\text { Eye tracking with moving } \\
\text { stimulus at different speeds }\end{array}$ \\
\hline
\end{tabular}

\begin{tabular}{|c|c|c|c|}
\hline $\begin{array}{l}\text { Pesce et al. } \\
(2007) \text { [87] }\end{array}$ & $60-75$ & 25 & Cycling (strength, aerobic) \\
\hline $\begin{array}{l}\text { Lobjois et al., } \\
\text { (2008) [98] }\end{array}$ & $20-80$ & 48 & $\begin{array}{l}\text { Tennis (aerobic, strength, } \\
\text { balance, coordination) }\end{array}$ \\
\hline $\begin{array}{l}\text { Marmeleira et al. } \\
(2009)[71]\end{array}$ & $60-82$ & 32 & $\begin{array}{l}\text { Aerobic fitness with cognitive } \\
\text { demands }\end{array}$ \\
\hline
\end{tabular}

\begin{tabular}{|c|c|c|c|}
\hline $\begin{array}{l}\text { Schorer \& Baker } \\
\text { (2009) [96] }\end{array}$ & $14-51$ & 34 & $\begin{array}{l}\text { Handball (aerobic, strength, } \\
\text { balance, coordination) }\end{array}$ \\
\hline $\begin{array}{l}\text { Voss et al. } \\
(2010) \text { [35] }\end{array}$ & $55-80$ & 120 & Aerobic \\
\hline $\begin{array}{l}\text { Voelcker-Rehage } \\
\text { et al. (2010) [28] }\end{array}$ & $65-72$ & 72 & $\begin{array}{l}\text { A battery of fitness tests to } \\
\text { assess physical and motor fitness } \\
\text { (cardiovascular, muscular } \\
\text { strength, movement speed, } \\
\text { balance, motor coordination } \\
\text { and flexibility) }\end{array}$ \\
\hline
\end{tabular}

Pesce et al. $\quad 60-80 \quad 48 \quad$ Cycling (strength, aerobic)

(2011) [70]

Marmeleira et al. $\quad 61-81 \quad 38$

(2012) [89]

$\begin{aligned} & \text { Hung \& Kruse } \\ & \text { (2012) [72] }\end{aligned}$
$\begin{aligned} & \text { Ballesteros et al. } \\ & \text { (2013) [1] }\end{aligned}$

Visuospatial attention

Track and response to a moving stimulus in a conscience timing task

Reaction time, speed processing, movement time, divided attention, peripheral vision, psychomotor performance and executive function

Eye tracking with moving stimulus

Visuospatial attention

Executive control, processing speed

Visuospatial attention

Peripheral vision

Motor speed, visual attention

Tai-chi (strength, member coordination, balance and cognitive)

Regular physical exercise (e.g., swimming, playing tennis, playing golf, or fitness training)

Executive control and processing speed
Significant findings

Tracking abilities tended to improve with aerobic exercise.

Reported physical activity was correlated with a better performance in performing a useful field of view task.

Reaction time and visual detection was better in the physically active group.

Worse cardiorespiratory fitness at baseline leads to lower scores on attention and executive function tests.

Reported physical activity was not correlated with a better performance in a useful field of view task.

All participants performed worst when the velocity of the moving stimulus increased but older non-players showed a higher pronounced effect.

Physically active older adults show better visuospatial attention than sedentary older adults.

Non-players exhibited more errors than players, especially in the 70-80 year old group.

Exercise enhanced reaction time, speed visual processing and divided attention (though the useful field of view) and lower limb mobility.

Age-declines seem to be more related to motor rather to perception.

Increase in functional connectivity correlated with aerobic exercise and might lead to an improved visuospatial attention.

Physical and motor fitness are both related to an improved executive control and perceptual speed.

Older road cyclists show better visual attention than sedentary older adults.

Reported physical activity correlated with better performance in a useful field of view task.

Older Tai-chi practitioners were faster and had better visual attention than non-athletes of the same age. executive control and processing
Exercise was related to better speed in older adults. 
Table 2 Characteristics and main findings of perceptual and cognitive skills and physical activity studies of older adults (Continued)

\begin{tabular}{|c|c|c|c|c|c|}
\hline Study & $\begin{array}{l}\text { Age } \\
\text { range }\end{array}$ & Number & Type of exercise & Structures/processes investigated & Significant findings \\
\hline $\begin{array}{l}\text { Muiños \& } \\
\text { Ballesteros } \\
\text { (2014) [26] }\end{array}$ & $19-68$ & 45 & $\begin{array}{l}\text { Karate and judo (aerobic, } \\
\text { strength, member coordination, } \\
\text { balance) }\end{array}$ & Peripheral vision & $\begin{array}{l}\text { The practice of martial arts was } \\
\text { related to better peripheral vision. }\end{array}$ \\
\hline $\begin{array}{l}\text { Muiños \& } \\
\text { Ballesteros } \\
(2015)[27]\end{array}$ & $19-68$ & 135 & $\begin{array}{l}\text { Karate and judo (aerobic, } \\
\text { strength, member coordination, } \\
\text { balance) }\end{array}$ & Dynamic visual acuity & $\begin{array}{l}\text { Martial arts practitioners showed } \\
\text { better dynamic visual acuity } \\
\text { compared to sedentary older } \\
\text { adults. }\end{array}$ \\
\hline $\begin{array}{l}\text { Ando et al. } \\
\text { (2017) [88] }\end{array}$ & $65-74$ & 30 & Not specified & Peripheral vision & $\begin{array}{l}\text { The more intensive the physical } \\
\text { activity, the better performance is } \\
\text { obtained in the Useful Field of } \\
\text { View. }\end{array}$ \\
\hline $\begin{array}{l}\text { Miller et al. } \\
\text { (2017) [73] }\end{array}$ & $67-79$ & 90 & $\begin{array}{l}\text { Tai-chi (strength, member } \\
\text { coordination, balance and } \\
\text { cognitive) }\end{array}$ & $\begin{array}{l}\text { Executive function, visual } \\
\text { attention, peripheral vision }\end{array}$ & $\begin{array}{l}\text { Tai-Chi practice correlated with } \\
\text { the improvement of cognitive } \\
\text { functioning and peripheral vision. }\end{array}$ \\
\hline $\begin{array}{l}\text { Zettel-Watson } \\
\text { et al. (2017) [54] }\end{array}$ & $52-89$ & 50 & $\begin{array}{l}\text { Functional mobility, balance, } \\
\text { lower body strength, gait, and } \\
\text { aerobic endurance }\end{array}$ & $\begin{array}{l}\text { Physical measures, executive } \\
\text { function }\end{array}$ & $\begin{array}{l}\text { Physical performance related to } \\
\text { dynamic balance and aerobic } \\
\text { endurance was associated with } \\
\text { an enhanced processing speed, } \\
\text { inhibition and working memory. }\end{array}$ \\
\hline $\begin{array}{l}\text { Huebner et al. } \\
\text { (2017) [55] }\end{array}$ & $65-74$ & 30 & Aerobic & Fine motor skills & $\begin{array}{l}\text { Aerobic exercise improves motor } \\
\text { learning. }\end{array}$ \\
\hline
\end{tabular}

Note: Studies are organized by publication year. The corresponding reference appears in brackets

exercises, some studies have investigated the combination of physical and cognitive training with video games. Exergame training could be a perfect activity for homebound older adults with lower education levels or who are reluctant to leave the house to participate in outdoor activities. The study of Eggenberger et al. [65] compared balance and stretching training with cognitive-motor video game dancing and showed that the video game dance group showed a greater reduction in left prefrontal cortex activity and also improved executive functions. Schättin et al. [66] found greater prefrontal theta activity and improved cognitive functioning in the exergame group than in the group participating in a classic balance activity. A recent training study with multiple neuroimaging measures [25] conducted with adults over 60 years of age showed that memory and executive functions improved after a sixweek multi-domain exercise program that included aerobic, balance, weight lifting, and yoga carried out with a video game (Wii-fitness). Their magnetic resonance imaging (MRI) data revealed different levels of striatum volume loss, which was higher for controls than for the exercise group. The study [25] also found other brain differences between the exercise and control groups in the cingulate, temporal, parietal, and occipital regions.

Dance might also be a form of PA that combines exercise with cognitive factors and thus have stronger and longer-lasting effects on the brain and on executive functioning than conventional and repetitive physical exercises. For example, Müller et al. [67] investigated the effects on neuroplasticity of dance compared to conventional and repetitive fitness exercises (strength- endurance and flexibility training) in healthy older adults. After a training period, the dance group showed increased gray matter volume in the left precentral gyrus and enhanced performance in the attention and memory tests compared to the fitness group. In another study comparing conventional exercises (endurance, strength and flexibility) with dancing, results showed that although left hippocampal volume increased in both groups, only dancers showed increases in the left dentate gyrus and the right subiculum and improved performance in the balance tests [68]. In a recent study [69], however, no differences in brain volume or cognitive functioning were observed between two groups of physically active older adults; one group included adults engaged in various moderate sports activities, and the other were members of a dancing class. The lack of difference might be due to the low or moderate training of the dance group (once or twice a week).

To sum up, neuroimaging and behavioral studies have shown the different effects produced in cognition and brain functions as a result of the type of PA (see Tables 1 and 2). It seems that aerobic and cardiovascular fitness, compared to other types of exercise (nonaerobic), are associated with larger hippocampal volume that translates into improved memory [35, 43, 50]. Aerobic and cardiovascular exercises in older adults also seem to increase both brain volume in gray matter regions [45, 52], BDNF levels [43, 45] and neural connectivity that might be associated to better cognitive performance in executive functioning and spatial memory tasks [35, 43]. In general, this might result in better attention and 
inhibition of distracting information, making the older brain more flexible and efficient [31, 33, 60, 70, 71]. Most research has focused in aerobic/cardiorespiratory activity although motor fitness plays also an important role. Coordination training also improves cognitive functioning in older adults $[28,51,60]$. This type of exercise seems to be also involved in perceptual speed and in the visual-spatial network $[28,60,72,73]$. This is not surprising given that coordination activity is based on: balance, eye-hand and/or leg-arm coordination and spatial orientation skills, and it also may require interacting with persons and other objects in the environment. Motor coordination may be also involved in cognitive processes like attention so as to coordinate or to prepare anticipatory movements. Visual-spatial areas might be working to train all these abilities. The effect of a combined training program including aerobic, coordination and cognitive demands is one of the best ways to improve cognition from a comprehensive point of view; this might be the case of dancing. In general, dancing seems to produce similar benefits to aerobic activities to improve cognition; this is shown by some studies, which found no differences (for example, in gray matter volume [69]) between dancers and practitioners in other aerobic exercises. Other studies have reported increased gray matter volume as well as improved attention and memory functions [67] in dancers compared to other nonaerobic PA. Increases in volume in some areas of the hippocampus as well as improvements in balance tasks (68) have also been reported in dancers compared to the practice of other types of exercises such as strength-endurance and flexibility. These increases lead to a larger reduction in the left prefrontal cortex activity thus improving executive functions in dancers compared to balance and stretching exercise practitioners.

The relations between aging, physical exercise and cognition have been widely investigated. However, there has been little research of the relationship between physical exercise, aging and perception, notably with regard to visuospatial skills. Visual abilities are closely linked to cognition and they are needed to understand and interpret the visual scene. In fact, some studies suggest that large proportions of the age-related variance in cognitive variables might be due to sensory (e.g., visual) rather than cognitive decline [74].

In the next section, we review the role of visuospatial attention in daily living and include studies that have shown the benefits to older adults of regular PA of different types, especially martial arts.

\section{Visuospatial attention}

Visuospatial attention plays a central role in the performance of a variety of activities that are critical for an active and independent life. It is important for processing visual information and perceiving moving stimuli that appear in different areas of the visual field. Aging is associated with a decline in visual tracking abilities, lower accuracy in pursuing targets [75], a decline in saccade direction accuracy [76], difficulty perceiving moving stimuli [77], and poor performance in visual search tasks [78]. Furthermore, spatial location of stimuli in the visual field [79] and peripheral vision decline with age, especially at high eccentricities [26, 27, 80-83] (from $5^{\circ}$ of visual angle from fixation). Control of all these factors, amongst others, may be critical when attributing results to differences in cognitive processing, since some studies [84] found that after controlling for visual acuity, the age-related decline in P3b amplitude (an event-related potential -ERPcomponent related to decision-making/updating) in response to visual targets disappeared, suggesting that in some cases results might be due to sensory and not to cognitive processing. However, another ERP study [85] found that the prolongation of motor responses, rather than sensory factors, could account for the agerelated differences. Specifically, the study found lower activation patterns over the contralateral motor cortex, responsible for generating motor responses.

Visuospatial attention improves with PA (see Table 2). A series of studies support the idea that physical activity make older adults more efficient than sedentary individuals in reaction time tasks, detecting stimuli located at the periphery of the visual field [86], and they are faster at identifying small details of moving stimuli [72]. At the same time, they show greater flexibility in attentionorientation tasks [70, 87]. However, any such visual advantages are not usually attributed to the existence of a superior visual system but the visual system might be more efficient in certain contexts [72]. Differences in the visual perception of athletes could therefore be related to the visual strategy used [visual network], possibly derived from a long and effortful learning process.

Although it is not known whether the abilities of athletes are innate or acquired after years of practice, the latter is generally considered more likely [72], as athletes acquire different skills depending on the type of sport involved. The type of motor learning that occurs in each case seems to be the basis of the visual skills shown by the athletes. An important question is whether the automation process involved in each case leads to the transfer of these skills to other basic tasks (not related to their sport), for example, in the rapid detection of items that appear in different parts of the visual field, including peripheral areas.

Peripheral vision (PV) is a crucial visuospatial skill that refers to the perception of stimuli that are outside the central part of the visual field. The more eccentric or distant from fixation the visual stimulus is, the more difficult it is to detect and the longer the reaction time required. 
Peripheral vision is crucial for the analysis of the environment and plays an important role in our daily life. The fast detection of a stimulus that appears in the peripheral visual field is critical, especially for older individuals, who may often suffer falls that can be due to poor detection of obstacles located in their peripheral visual field. Regular PA decreases overall reaction time, favors the rapid perception of stimuli, and improves visual attention in older adults [70, 72, 86, 87].

Martial arts, as a fast moving sport, depending on movements tends to pay attention to what happens laterally, might be a perfect candidate to study PV. A study with young and older participants [26] investigated whether judo and karate athletes exhibit better peripheral vision skills than non-athletes of the same age, and whether there were differences depending on the type of sport. The study included younger and older judo and karate athletes and sedentary participants of the same age. Results showed that young karate athletes performed faster than both young judo athletes and non-athletes when stimuli appeared at the periphery of the visual field suggesting that this type of sport in the young group was important. It seems that karate, develops a set of skills that improve peripheral vision to a greater extent than judo. Importantly, for the older groups, both judo and karate athletes showed better peripheral skills than sedentary participants of the same age. However, there were no differences between judo and karate practitioners. A study with Tai-Chi practitioners aged 65 years and over revealed that they were more accurate and showed faster reaction times in a peripheral vision task than sedentary adults of the same age [73]. The results of that study also showed that Tai-Chi practitioners scored better on the rest of the subtests, which included visual search and cognitive tasks related to executive control.

A recent study conducted with older adults [88] also found an association between PA and the visual function. Specifically, more vigorous PA led to better performance on the Useful Field of View test (widely used to assess peripheral vision). Other studies conducted with older participants [86, 71, 89] also reported an association between PA and better scores on the Useful Field of View test. The two latter studies [71, 89] did not evaluate the PA itself, but used questionnaires to collect information about the participants' PA. Unfortunately, these questionnaires did not assess accurately the type, intensity, or duration of the exercise. Another study [90], however, did not find any relationship between PA (also reported by participants with a questionnaire) and performance on the Useful Field of View test.

In sum, PV is a crucial ability for daily life that seems to improve with PA in both young and older adults. However, the exact mechanisms whereby exercise might act on the improvement and/or maintenance of PV abilities and the type of exercise still remain unclear. More studies are needed to clarify this question, especially in relation to older observers.

Gaze behavior is also a visuospatial factor that has important implications in our daily life as "where" and "when" we are looking is crucial. Although the analysis of gaze behavior and PA (for example, fixation frequency and duration, or reaction time to detect stimuli as a function of the location in the visual field) has attracted the attention of researchers, this area has been poorly investigated in older adults. In general, the way of perceiving usually converts the visual scene into an ellipse, with better detection of stimuli on the horizontal than on the vertical plane [91]. Moreover, it seems that gaze behavior changes with age, since some studies have found a relationship between aging, a decrease in stimuli detection in the lower areas of the visual field, and accidents and falls [92]. An important question is whether this perceptual pattern changes as a function of age and physical activity. A study with young and older karate and judo athletes and non-athletes [26] reported a horizontalvertical anisotropy and a vertical meridian asymmetry. All groups detected stimuli presented on the horizontal meridian faster than those on the vertical meridian. They also detected stimuli in the lower visual areas faster than those in the upper areas. Here, age and sport did not modify the way of perceiving a visual scene. These results suggest that visual asymmetries occur at all ages and are basically unrelated to PA, but more research is needed to clarify this finding, as, to our knowledge, this is the only study focusing on aging, PA and perceptual asymmetries. Given the importance of this visuospatial skill, especially in the elderly to prevent falls and other types of accidents, more research is needed to investigate whether exercise might modify gaze behavior.

Another visuospatial ability needed to interact with the environment is dynamic visual acuity (DVA), which refers to the ability to resolve fine spatial details of an object when there is relative motion between the observer and the object [93]. DVA skills are necessary because the world around us is full of moving stimuli that we must be able to detect. These stimuli may appear following multiple trajectories, at different contrasts and at different speeds. DVA is a visuomotor skill that can also play an important role in the lives of elders given the large number of stimuli in motion that exist in our daily life. This type of visual ability, however, is one of the first to decline with age [94], along with the ability to track stimuli [75] and to perform saccadic movements in the right direction [76]. All these visual skills may be related to processing speed.

As with peripheral vision, using basic stimuli not related to the participants' sport, several studies have reported differences between older athletes and nonathletes in the rapid detection of moving stimuli [27]. When playing sports, stimuli usually move, and athletes might 
develop a series of skills to enable better and faster detection of stimuli moving in several trajectories. Muiños and Ballesteros presented moving stimuli to both young and older groups of athletes and non-athletes and found that young and older athletes obtained higher DVA scores than non-athletes of the same age [27]. The results suggest that martial arts activity tends to preserve general DVA skills. Moreover, all the older participants showed similar and greater oblique effects. These results indicate that playing a sport does not preserve the ability to detect stimuli that move obliquely. Importantly, the differences between the older groups were greater and mainly concentrated in the high velocity condition.

Surprisingly, there is a lack of research investigating DVA with older athletes or older adults who play a sport on a regular basis. The studies that demonstrate a correlation between improved DVA and certain sports have been conducted with young participants. However, only a few studies have investigated the ability of physically active older adults to track moving stimuli. Accuracy while tracking moving stimuli is a basic ability assessed by dynamic visual acuity (DVA) tests. Bakken et al. [95] showed that after 8 weeks of aerobic exercise, older adults tracked moving stimuli better than at pretest (before training) and than the control group. A further study [96] also assessed eye-tracking ability to a moving stimulus. The participants were five age groups of skilled handball athletes. The oldest group included athletes aged between 43 and 51 years, and could be considered a young-old group. The results showed age-related declines in motor performance but not in perceptual performance, as seniors showed similar fixations (e.g., number, duration) as skilled younger athletes. Lobjois et al. [97] also reported better performance of physically active older adults when tracking a moving stimulus at different speeds. With increasing speed, the performance of all age groups decreased, as it becomes increasingly difficult to track and to detect the features of an object as speed increases. However, when the speed of the moving object increased, older tennis players performed better than older sedentary participants. A further study [98] with tennis players yielded similar results, showing that non-players of all ages (from 20 to 80) showed more errors responding to a stimulus with apparent movement. It is important to note that the differences between players and non-players were greater in the oldest group (70-80 years of age). Another study [99] used a moving dot on the screen to monitor saccades and eye movements, showing that the physically active older participants were more accurate and also showed superior posture control than non-active individuals.

To sum up, physically active individuals, especially those who engage in ball sports or fast-moving sports, such as tennis or martial arts, usually show better DVA or tracking abilities to a moving stimulus than sedentary individuals. When people age, sport helps to preserve their dynamic visual skills. However, given that tracking visual stimuli in general (including DVA) is one of the first abilities to decline with age, it may not be preserved by sports activity, especially for the oldest groups (e.g. 70-80 years old) and with objects on oblique trajectories. Taking part in a sport or being physically active might help generate a more appropriate motor response to a moving stimulus.

\section{Conclusions}

Older adults are particularly prone to falls or accidents that could largely be due to declines in many perceptual and cognitive abilities (e.g., poor reaction time and processing speed, loss in peripheral vision, attention decline). According to the reviewed literature, PA might partially attenuate such age-related perceptual and cognitive declines, and even delay the onset of neurodegenerative diseases such as Alzheimer's, in various ways, including delaying brain volume loss in certain areas such as the hippocampus, acting on both gray and white matter, and enhancing brain connectivity. These changes in some brain areas and in functional connectivity may be reflected at a behavioral level, with improvements in many cognitive functions such as memory, processing and perceptual speed, attention, etc. One of the major questions in research is which type of PA leads to greater improvement. On this point, the literature contains different results as a function of the type of exercise. In general, aerobic exercise seems to be the most effective for improving cognitive areas, but researchers have also reported cognitive improvements with activities that require limb coordination. Aerobic and coordination exercises seem to be more beneficial to cognitive processes than other exercises such as stretching or balancing. However, studies generally report greater cognitive improvements with multi-domain training, involving both physical and cognitive exercises [38]. This could be the case of exergames, dancing and, perhaps to a lesser extent, some complex sports like martial arts. Exergames use video games to provide physical exercise. They comprise different types of exercise, including aerobic, coordination, balance, and cognition, which could produce different physical and cognitive changes. One of the main advantages of using this method, especially for older adults, is that the exercises can be done indoors, increasing the probability of doing them. Moreover, video games can be more enjoyable than classic keep-fit classes, as well as more comfortable and relaxing. Dancing shares many of these advantages, as it usually involves aerobic, coordination, balance and cognitive work (e.g., learning a dance routine). Another common feature is that they are both enjoyable and can be carried out as a leisure activity. Dancing also involves social contact, and it is well known that an active social life is one of the main factors of healthy aging. 
A great deal of research on aging and PA has focused on cognitive changes, but little is known about visuospatial attention. It is widely accepted that peripheral vision deteriorates with age, but PA can improve it in both young and older individuals. The same is true for tracking abilities. Both skills are needed to interpret visual scenes and are important in everyday life. There are some types of sport that are more likely to improve PV, notably some martial arts, especially those that require paying attention to what is happening laterally. Some sports can improve DVA or tracking abilities more than others, particularly ball sports and martial arts. Eye function plays an important role for elders, as the way we see the world, where we look and when, can have critical implications. Further studies are needed to clarify all these issues.

\section{Abbreviations}

BDNF: Brain-Derived Neurotrophic Factor; DVA: Dynamic visual acuity; ERP: Event-related potential; fMRI: Functional magnetic resonance imaging; MRI: Magnetic resonance imaging; PA: Physical activity; PV: Peripheral vision

\section{Acknowledgements}

This work was supported by grants from the Spanish Government (Grants PSI2013-41409-R and PSI2016-80377-R). The funder had no role in the decision to publish or in the preparation of the manuscript.

\section{Funding}

Grants PSI2013-41409-R and PSI2016-80377-R.

\section{Availability of data and materials}

Not applicable

\section{Authors' contributions}

MM and SB participated in the elaboration and preparation of the manuscript. Both authors read and approved the final manuscript.

\section{Ethics approval and consent to participate}

Not applicable

\section{Consent for publication}

Yes

\section{Competing interests}

The authors declare that they have no competing interests.

\section{Publisher's Note}

Springer Nature remains neutral with regard to jurisdictional claims in published maps and institutional affiliations.

\section{Author details}

'Department of Psychology, Universidad Isabel I, Calle de Fernán González, 76, 09003 Burgos, Spain. ${ }^{2}$ Studies on Aging and Neurodegenerative Diseases Research Group, Department of Basic Psychology II, Universidad Nacional de Educación a Distancia, Madrid, Spain.

Received: 26 September 2017 Accepted: 20 February 2018

Published online: 26 February 2018

\section{References}

1. Ballesteros S, Mayas J, Reales JM. Does a physically active lifestyle attenuate decline in all cognitive functions in old age? Curr Aging Sci. 2013a;6:189-98. https://doi.org/10.2174/18746098112059990001.

2. Ballesteros S, Reales JM. Intact haptic priming in normal aging and Alzheimer's disease: evidence for dissociable memory systems. Neuropsychologia. 2004:42:1063-70. https://doi.org/10.1016/j. neuropsychologia.2003.12.008.
3. Ballesteros S, Reales JM, Mayas J, Heller MA. Selective attention modulates visual and haptic repetition priming: effects in aging and Alzheimer's disease. Exp Brain Res. 2008;189:473-83. https://doi.org/10.1007/s00221-008-1441-6.

4. Berntsen D, Rasmussen AS, Miles AN, Nielsen NP, Ramsgaard SB. Spontaneous or intentional? Involuntary versus voluntary episodic memories in older and younger adults. Psychol Aging. 2017;32:192-201. https://doi.org/10.1037/pag0000157.

5. Davis HP, Trussell LH, Klebe KJ. A ten-year longitudinal examination of repetition priming, incidental recall, free recall, and recognition in young and elderly. Brain Cogn. 2001;46:99-104. https://doi.org/10.1016/S02782626[01]80043-9

6. Park DC, Lautenschlager G, Hedden T, Davidson NS, Smith AD, Smith PK Models of visuospatial and verbal memory across the adult life span. Psychol Aging. 2002;17:299-320. https://doi.org/10.1037/0882-7974.17.2.299

7. Park DC, Reuter-Lorenz PA. The adaptive brain: aging and neurocognitive scaffolding. Annu Rev Psychol. 2009;60:173-96.

8. Baltes PB. The aging mind: potential and limits. Gerontologist. 1993:33:580-94

9. Owsley C, McGwin G, Searcey K. A population-based examination of the visual and ophthalmological characteristics of licensed drivers aged 70 and older. J Gerontol Ser A-Biol Sci Med Sci. 2013;68:567-73. https://doi.org/10.1093/gerona/gls183.

10. Salthouse TA. The processing speed theory of adult age differences in cognition. Psychol Rev. 1996;103:403-28. https://doi.org/10.1037/0033-295X. 103.3.403

11. Park DC, Puglisi JT. Older adults' memory for the color of pictures and words. J Gerontol. 1983:40:198-204. https://doi.org/10.1093/geronj/40.2.198

12. Zacks RT, Hasher L, Li KZH. Human memory. In: Craik Fl, Salthouse TA, editors. The handbook of aging and cognition. 2nd ed. Mahwah: Lawrence Erlbaum Associates; 2000. p. 293-358.

13. Reuter-Lorenz PA, Jonides J, Smith EE, Hartley A, Miller A, Marshuetz C, Koeppe RA. Age differences in the frontal lateralization of verbal and spatial working memory revealed by PET. J Cogn Neurosci. 2000;12:174-87.

14. Cabeza R, Grady CL, Nyberg L, McIntosh AR, Tulving E, et al. Age-related differences in neural activity during memory encoding and retrieval: a positron emission tomography study. J Neurosci. 1997;17:391-400.

15. Grady CL, Mclntosh AR, Rajah MN, Beig S, Craik Fl. The effects of age on the neural correlates of episodic encoding. Cereb Cortex. 1999;9:805-14.

16. Reuter-Lorenz PA, Park DC. How does it STAC up? Revisiting the scaffolding theory of aging and cognition. Neuropsychol Rev. 2014;24:355-70.

17. Jiang X, Petok JR, Howard DV, Howard JH. Individual differences in cognitive function in older adults predicted by neuronal selectivity at corresponding brain regions. Front Aging Neurosci. 2017;9:103. https://doi.org/10.3389/ fnagi.2017.00103.

18. Bavelier D, Neville HJ. Cross-modal plasticity: where and how? Nat. Rev. Neurosci. 2002;3:443-52. https://doi.org/10.1038/nrn848.

19. Hötting K, Röder B. Beneficial effects of physical exercise on neuroplasticity and cognition. Neurosci Biobehav Rev. 2013;37:2243-57. https://doi.org/10. 1016/j.neubiorev.2013.04.005.

20. Andel R, Crowe M, Pedersen NL, Fratiglioni L, Johansson B, Gatz M. Physical exercise at midlife and risk of dementia three decades later: a populationbased study of Swedish twins. J Gerontol A Biol Sci Med Sci. 2008;63:62-6. https://doi.org/10.1093/gerona/63.1.62

21. Larson EB, Wang L, Bowen JD, McCormick WC, Teri L, Crane P, Kukull W. Exercise is associated with reduced risk for incident dementia among persons 65 years of age and older. Ann Intern Med. 2006;17:73-81. https:// doi.org/10.7326/0003-4819-144-2-200601170-00004.

22. Rovio S, Kareholt I, Helkala EE, Viitanen M, Winblad B, Tuomilehto J, Soininen $\mathrm{H}$, Nissinen A, Kivipelto M. Leisure-time physical activity at midlife and the risk of dementia and Alzheimer's disease. Lancet Neurol. 2005;4:705-11. https://doi.org/10.1016/S1474-4422[05]70198-8

23. Ball K, Owsley C, Sloane ME, Roenker DL, Bruni JR. Visual attention problems as a predictor of vehicle crashes in older drivers. Invest Ophthalmol Vis Sci. 1993:34:3110-23.

24. Glisky EL. Changes in cognitive function in human aging. In: Riddle DR, editor. Brain aging: models, methods, and mechanisms. Boca Raton: CRC Press; 2007.

25. Ji L, Zhang H, Potter GG, Zang YF, Steffens DC, Guo H, Wang L. Multiple neuroimaging measures for examining exercise-induced neuroplasticity in older adults: a quasi-experimental study. Front Aging Neurosci. 2017;9:102. http://doi.org/10.3389/fnagi.2017.00102

26. Muiños M, Ballesteros S. Peripheral vision and perceptual asymmetries in young and older martial arts athletes and nonathletes. Atten Percept Psychophys. 2014;76:2465-76. https://doi.org/10.1068/p7567. 
27. Muiños M, Ballesteros S. Sport can protect dynamic visual acuity from aging: a study with young and older judo and karate martial arts athletes. Atten Percept Psychophys. 2015;77:2061-73. https://doi.org/10. 3758/s13414-015-0901-X

28. Voelcker-Rehage C, Godde B, Staudinger UM. Physical and motor fitness are both related to cognition in old age. Eur J Neurosci. 2010;31:167-76. https:// doi.org/10.1111/j.1460-9568.2009.07014.x.

29. Chaddock L, Hillman CH, Buck SM, Cohen NJ. Aerobic fitness and executive control of relational memory in preadolescent children. Med Sci Sports Exerc. 2011;43:344-9. https://doi.org/10.1249/MSS.0b013e3181e9af48.

30. Peters J, Dauvermann M, Mette C, Platen P, Franke J, Hinrich T, Daum I. Voxel-based morphometry reveals an association between aerobic capacity and grey matter density in the right anterior insula. Neuroscience. 2009;163: 1102-8. https://doi.org/10.1016/j.neuroscience.2009.07.030

31. Barnes DE, Yaffe K, Satariano WA, Tager IB. A longitudinal study of cardiorespiratory fitness and cognitive function in healthy older adults. J Am Geriatr Soc. 2003;51:459-65. https://doi.org/10.1046/j.1532-5415.2003.51153.x.

32. Chodzko-Zajko WJ, Moore KA. Physical fitness and cognitive functions in aging. Exerc Sport Sci Rev. 1994;22:195-220.

33. Colcombe SJ, Kramer AF, Erickson KI, Scalf P, McAuley E, Cohen NJ, Webb A, Jerome GJ, Márquez DX, Elavsky S. Cardiovascular fitness, cortical plasticity, and aging. Proc Natl Acad Sci. 2004;101:3316-21. https://doi.org/10.1073/ pnas.0400266101.

34. Hötting K, Schauenburg G, Röder B. Long-term effects of physical exercise on verbal learning and memory in middle-aged adults: results of a one-year follow-up study. Brain Sci. 2012;2:332-46. https://doi.org/10.3390/ brainsci2030332

35. Voss MW, Erickson Kl, Prakash RS, Chaddock L, Malkowski E, Alves H, Kim JS, Morris KS, White SM, Wojcicki TR, Hu L, Szabo A, Klamm E, McAuley E, Kramer AF. Functional connectivity: a source of variance in the association between cardiorespiratory fitness and cognition? Neuropsychologia. 2010; 48:1394-406. https://doi.org/10.1016/j.neuropsychologia.2010.01.005

36. Voss MW, Nagamatsu LS, Liu-Ambrose T, Kramer AF. Exercise, brain, and cognition across the life span. J Appl Psychol. 2011;111:1505-13. https://doi. org/10.1152/japplphysiol.00210.2011.

37. Kliegl R, Smith J, Baltes PB. On the locus and process of magnification of age differences during mnemonic training. Dev Psychol. 1990;26:894-904. https://doi.org/10.1037/0012-1649.26.6.894

38. Ballesteros S, Kraft E, Santana S, Tziraki C. Maintaining older brain functionality: a targeted review. Neurosci Biobehav Rev. 2015;55:453-77.

39. Thompson PD, Buchner D, Pina IL, Balady GJ, Williams MA, Marcus BH, Berra K, Blair SN, Costa F, Franklin B, Fletcher GF, Gordon NF, Pate RR, Rodriguez BL, Yancey AK, Wenger NK. Exercise and physical activity in the prevention and treatment of atherosclerotic cardiovascular disease: a statement from the council on clinical cardiology and the council on nutrition, physical activity, and metabolism. Circulation. 2003;24:3109-16.

40. Voelcker-Rehage C, Niemann C. Structural and functional brain changes relate to different types of physical activity across the life span. Neurosci Biobehav Rev. 2013;37:2268-95. https://doi.org/10.1016/j.neubiorev.2013.01.028

41. Lin TW, Shih YH, Chen SJ, Lien CH, Chang CY, Huang TY, Chen SH, Jen CJ, Kuo YM. Running exercise delays neurodegeneration in amygdala and hippocampus of Alzheimer's disease (APP/PS1) transgenic mice. Neurobiol Learn Mem. 2015:118:189-97.

42. Erickson Kl, Kramer AF. Aerobic exercise effects on cognitive and neural plasticity in older adults. Br J Sports Med. 2009:43:22-4. https://doi.org/10. 1136/bjsm.2008.052498.

43. Erickson KI, Voss MW, Prakash RS, Basak C, Szabo A, Chaddock L, Kim JS, Heo S, Alves H, White SM, Wojcicki TR, Mailey E, Vieira VJ, Martin SA, Pence BD, Woods JA, McAuley E, Kramer AF. Exercise training increases size of hippocampus and improves memory. Proc Natl Acad Sci. 2010;108:3017-22. https://doi.org/10.1073/pnas.1015950108.

44. Raz N, Rodrigue KM. Differential aging of the brain: patterns, cognitive correlates and modifiers. Neurosci Biobehav Rev. 2006;30:730-48. https://doi. org/10.1016/j.neubiorev.2006.07.001

45. Ruscheweyh R, Willemer C, Krüger K, Duning T, Warnecke T, Sommera J, Völker K, Hod HV, Mooren F, Knecht S, Flöel A. Physical activity and memory functions: an interventional study. Neurobiol Aging. 2011;32:1304-19. https://doi.org/10.1016/j.neurobiolaging.2009.08.001.

46. Lee R, Kermani P, Teng KK, Hempstead BL. Regulation of cell survival by secreted proneurotrophins. Science. 2001;294:1945-8. https://doi.org/10. 1126/science.1065057
47. Bekinschtein P, Cammarota M, Katche C, Slipczuk L, Rossato Jl, Goldin A, Izquierdo I, Medina JH. BDNF is essential to promote persistence of longterm memory storage. Proc Natl Acad Sci. 2008;105:2711-6. https://doi.org/ 10.1073/pnas.0711863105

48. Pang PT, Teng HK, Zaitsev E, Woo NT, Sakata K, Zhen S, Teng KK, Yung WH, Hempstead BL, Lu B. Cleavage of proBDNF by tPA/plasmin is essential for long-term hippocampal plasticity. Science. 2004;306:487-91. https://doi.org/ 10.1126/science.1100135.

49. Håkansson K, Ledreux A, Daffner K, Terjestam Y, Bergman P, Carlsson R, Kivipelto M, Winblad B, Granholm A, Mohammed A, Kadir H. BDNF responses in healthy older persons to 35 minutes of physical exercise, cognitive training, and mindfulness: associations with working memory function. J Alzheimers Dis. 2017;55:645-57. https://doi.org/10.3233/JAD160593.

50. Jonasson LS, Nyberg L, Kramer AF, Lundquist A, Riklund K, Boraxbekk CJ. Aerobic exercise intervention, cognitive performance, and brain structure: results from the physical influences on brain in aging (PHIBRA) study. Front aging Neurosci. 2017;18:336. https://doi.org/10.3389/fnagi.2016.00336

51. Niemann C, Godde B, Staudinger UM, Voelcker-Rehage C. Exercise-induced changes in basal ganglia volume and cognition in older adults. Neuroscience. 2014;281:147-63. http://dx.doi.org/10.1016/j.neuroscience.2014.09.033

52. Colcombe SJ, Erickson Kl, Scalf PE, Kim JS, Prakash R, McAuley E, Elavsky S, Marquez DX, Hu L, Kramer AF. Aerobic exercise training increases brain volume in aging humans. J Gerontol A Biol Sci Med Sci. 2006:61:1166-70.

53. Hayes SM, Hayes JP, Cadden M, Verfaellie M. A review of cardiorespiratory fitness-related neuroplasticity in the aging brain. Front Aging Neurosci. 2013;5:1-16. https://doi.org/10.3389/fnagi.2013.00031.

54. Zettel-Watson L, Suen M, Wehbe L, Rutledge DN, Cherry BJ. Aging well: processing speed inhibition and working memory related to balance and aerobic endurance. Geriatr Gerontol Int. 2017;17:108-15. https:/doi.org/10.1111/ggi.12682.

55. Huebner L, Godde B, Voelcker-Rehage C. Association of acute exercise and fine motor learning in older adults. Innov Aging. 2017;1:1158-9. https://doi. org/10.1093/geroni/igx004.4227.

56. Dunsky A, Netz Y. Physical activity and sport in advanced age: is it risky? A summary of data from articles published between 2000-2009. Curr Aging Sci. 2012;5:66-71. https://doi.org/10.2174/1874609811205010066.

57. Liu-Ambrose T, Nagamatsu LS, Graf P, Beattie BL, Ashe MC, Handy TC. Resistance training and executive functions: a 12-month randomized controlled trial. Arch Intern Med. 2010;170:170-8. https://doi.org/10.1001/ archinternmed.

58. Cassilhas RC, Lee KS, Fernandes J, Oliveira MG, Tufik S, Meeusen R, De Mello MT. Spatial memory is improved by aerobic and resistance exercise through divergent molecular mechanisms. Neuroscience. 2012;202:309-17. https:// doi.org/10.1016/j.neuroscience.2011.11.029.

59. Colcombe S, Kramer AF. Fitness effects on the cognitive function of older adults: a meta-analytic study. Psychol Sci. 2003;14:125-30.

60. Voelcker-Rehage C, Godde B, Staudinger UM. Cardiovascular and coordination training differentially improve cognitive performance and neural processing in older adults. Front Hum Neurosci. 2011;5:26. https://doi. org/10.3389/fnhum.2011.00026.

61. Godde B, Voelker-Rehage C. Cognitive resources necessary for motor control in older adults are reduced by walking and coordination training. Front Hum Neurosci. 2017;156 https://doi.org/10.3389/fnhum.2017.00156.

62. Chan JSY, Wong ACN, Liu Y, Yu J, Yan JH. Fencing expertise and physical fitness enhance action inhibition. Psychol Sport Exerc. 2011;12:509-14. https://doi.org/10.1016/j.psychsport.2011.04.006

63. Gliner JA, Matsen-Twisdale JA, Horvath SM, Maron MB. Visual evoked potentials and signal detection following a marathon race. Med Sci Sports Exerc. 1979;11:155-9.

64. Budde H, Voelcker-Rehage C, Pietrabyk-Kendziorra S, Ribeiro P, Tidow G. Acute coordinative exercise improves attentional performance in adolescents. Neurosci Lett. 2008;441:219-23. https://doi.org/10.1016/j.neulet.2008.06.024.

65. Eggenberger $\mathrm{P}$, Wolf $\mathrm{M}$, Schumann $\mathrm{M}$, DeBruin ED. Exergame and balance training modulate prefrontal brain activity during walking and enhance executive function in older adults. Front Aging Neurosci. 2016;8:66. https:// doi.org/10.3389/fnagi.2016.00066.

66. Schättin A, Arner R, Gennaro F, de Bruin ED. Adaptations of prefrontal brain activity, executive functions, and gait in healthy elderly following exergame and balance training: a randomized-controlled study. Front Aging Neurosci. 2016;8:278. https://doi.org/10.3389/fnagi.2016.00278. 
67. Müller P, Rehfeld K, Schmicker M, Hökelmann A, Dordevic M, Lessmann V, Brigadski T, Kaufmann J. Evolution of neuroplasticity in response to physical activity in old age: the case for dancing. Front Aging Neurosci. 2017;9:56. https://doi.org/10.3389/fnagi.2017.00056.

68. Rehfeld K, Müller P, Aye N, Schmicker M, Dordevic M, Kaufmann J, Hökelmann A, Müller NG. Dancing or fitness sport? The effects of two training programs on hippocampal plasticity and balance abilities in healthy seniors. Front Hum Neurosci. 2017;11:305. https://doi.org/10.3389/fnhum.2017.00305.

69. Niemann C, Godde B, Voelcker-Rehage C. Senior dance experience, cognitive performance, and brain volume in older women. Neural plasticity. 2016:1-10. https://doi.org/10.1155/2016/9837321

70. Pesce C, Cereatti L, Forte R, Crova C, Casella R. Acute and chronic exercise effects on attentional control in older road cyclists. Gerontology. 2011;57:121-8.

71. Marmeleira J, Godinho M, Fernandes O. The effects of an exercise program on several abilities associated with driving performance in older adults. Accid Anal Prev. 2009;41:90-7. https://doi.org/10.1016/j.aap.2008.09.008.

72. Hung M, Kruse A. A randomized controlled trial of tai chi for balance, sleep quality and cognitive performance in elderly Vietnamese. Clin Interv Aging 2012;7:183-90. https://doi.org/10.2147/CIA.S32600.

73. Miller S, Taylor-Piliae RE. The association between tai-chi exercise and safe driving performance among older adults: an observational study. J Sport Health Sci. 2017; https://doi.org/10.1016/j.jshs.2017.01.013.

74. Baltes PB, Lindenberger $U$. Emergence of powerful connection between sensory and cognitive functions across the adult life span: a new window to the study of cognitive aging? Psych of Aging. 1997;12:12-21.

75. Paquette C, Fung J. Old age affects gaze and postural coordination. Gait Posture. 2011;33:227-32. https://doi.org/10.1016/j.gaitpost. https://doi.org/10. 1146/annurev.psych.59.103006.093656

76. Butler KM, Zacks RT, Henderson JM. Suppression of reflexive saccades in younger and older adults: age comparisons on an antisaccade task. Mem Cogn. 1999;27:584-91. https://doi.org/10.3758/BF03211552

77. Ball K, Sekuler R. Improving visual perception in older observers. J Gerontol. 1986;41:176-82.

78. Hahn S, Buttaccio DR. Aging and guided visual search: the role of visual working memory. Aging Neuropsychol C. 2017; https://doi.org/10.1080/ 13825583.2017 .1344183$.

79. Owsley C, Burton-Danner K, Jackson GR. Aging and spatial location during feature search. Gerontology. 2000;46:300-5. doi: 22181

80. Ball K, Beard D, Roenker R, Miller D, Griggs D. Age and visual search: expanding the useful field of view. J Opt Soc Am. 1988;5:2210-9. https://doi. org/10.1364/JOSAA.5.002210

81. Ball K, Owsley C, Beard B. Clinical visual perimetry underestimates peripheral field problems in older adults. Clin Vis Sci. 1990;5:113-25.

82. Beurskens $\mathrm{R}$, Bock $\mathrm{O}$. Age-related decline of peripheral visual processing: the role of eye movements. Exp Brain Res. 2012;217:117-24. https://doi.org/10. 1007/s00221-011-2978-3

83. Itoh N, Fukuda T. Comparative study of eye movements in extent of central and peripheral vision and use by young and elderly walkers. Percept Mot Skills. 2002;94:1283-91. https://doi.org/10.2466/pms.2002.94.3c.1283.

84. Porto FHG, Tuscha ES, Foxa AM, Alperina BR, Holcombb PJ, Daffnera KR. One of the most well-established age-related changes in neural activity disappears after controlling for visual acuity. Neurolmage. 2016;130:115-22. https://doi.org/10.1016/j.neuroimage.2016.01.035

85. Yordanova J, Kolev V, Hohnsbein J, Falkenstein M. Sensorimotor slowing with ageing is mediated by a functional dysregulation of motor-generation processes: evidence from high-resolution event-related potentials. Brain. 2004;127:351-62. https://doi.org/10.1093/brain/awh042.

86. Roth DL, Goode KT, Clay OJ, Ball K. Association of physical activity and visual attention in older adults. J Aging Health. 2003;15:534-47. https://doi.org/10. 1177/0898264303253512.

87. Pesce C, Cereatti L, Casella R, Baldari C, Capranica L. Preservation of visual attention in older expert orienteers at rest and under physical effort. J Hum Kinet. 2007;29:78-99.

88. Ando T, Sakai H, Uchiyama Y. Association of physical activity and appetite with visual function related to driving competence in older adults. BMC Geriatr. 2017;17:96. https://doi.org/10.1186/s12877-017-0484-6.

89. Marmeleira J, Ferreira I, Melo F, Godinho M. Associations of physical activity with driving-related cognitive abilities in older drivers: an exploratory study. Percept Mot Skills. 2012;115:521-33.
90. Owsley C, McGwin G. Association between visual attention and mobility in older adults. J Am Geriatr Soc. 2004;52:1901-6. https://doi.org/10.1111/j. 1532-5415.2004.52516.x.

91. Li B, Peterson MR, Freeman RD. Oblique effect: a neural basis in the visual cortex. J Neurophysiol. 2003;90:204-17. https://doi.org/10.1152/jn.00954.2002.

92. Black AA, Wood JM, Lovie-Kitchin JE. Inferior visual field reductions are associated with poorer functional status among older adults with glaucoma. Ophthalmic Physiol Opt. 2011;31:283-91. https://doi.org/10.1111/j.1475-1313.2010.00811.x.

93. Miller JW, Ludvigh EL. The effect of relative motion on visual acuity. Surv Ophthalmol. 1962;7:83-116.

94. Long GM, Crambert RF. The nature and basis of age-related changes in dynamic visual acuity. Psychol Aging. 1990;5:138-43. http://dx.doi.org/10. 1037/0882-7974.5.1.138

95. Bakken R, James C, Di Fabio R, Erlandson T. Effect of aerobic exercise on tracking performance in elderly people: a pilot study. Phys Ther. 2001;81:1870-9.

96. Schorer J, Baker J. An exploratory study of aging and perceptual-motor expertise in handball goalkeepers. Exp Aging Res. 2009;35:1-19. https://doi. org/10.1080/03610730802544641.

97. Lobjois R, Benguigui N, Bertsch J. Aging and tennis playing in a coincidence-timing task with an accelerating object: the role of visuomotor delay. Res Q Exerc Sport. 2005;76:398-406.

98. Lobjois R, Benguigui N, Bertsch J, Broderick M. Collision avoidance behavior as a function of aging and tennis playing. Exp Brain Res. 2008;184:457-68. https://doi.org/10.1007/s00221-007-1117-7.

99. Gauchard G, Gangloff P, Jeandel C, Perrin P. Physical activity improves gaze and posture control in the elderly. Neurosci Res. 2003:45:409-17. https://doi. org/10.1016/S0168-0102(03)00008-7.

\section{Submit your next manuscript to BioMed Central and we will help you at every step:}

- We accept pre-submission inquiries

- Our selector tool helps you to find the most relevant journal

- We provide round the clock customer support

- Convenient online submission

- Thorough peer review

- Inclusion in PubMed and all major indexing services

- Maximum visibility for your research

Submit your manuscript at www.biomedcentral.com/submit
Biomed Central 